\title{
Effect of M Sand and Supplementary Cementitious Materials on Carbonation of Concrete
}

\author{
JaganSivamani
}

\begin{abstract}
Carbonation is one of the imperative properties that affect the durability of concrete especially in case of reinforced structures. In this present study, an attempt has been taken to study the effect of $M$ sand and other supplementary cementitious materials like silica fume, fly ash and steel slag as a partial replacement to cement. Different combinations with $M$ sand, river sand and combinations of $M$ sand and river sand with supplementary cementitious materials at water to cement ratio varying from 0.45 to 0.5 was studied. Results revealed that the complete replacement of river sand by $M$ sand reduced the rate of carbonation but addition of supplementary cementitious along with either river sand or $M$ sand resulted in increase over the rate of carbonation compared to conventional concrete.
\end{abstract}

Keywords:Carbonation, Fly Ash, M sand, Silica fume and Steel Slag

\section{INTRODUCTION}

Reinforced concrete is a composite material composed of concrete, a mixture of cement, fine aggregate, coarse aggregate and water reinforced with steel bars. Reinforcement is mainly provided below the neural axis of the concrete for the redistribution of moments to avoid catastrophic failure. Such reinforced concrete structures gets deteriorated either by physical/chemical means. One such chemical deterioration is the corrosion of reinforcement bars that occurs due to carbonation. Atmospheric $\mathrm{CO}_{2}$ enters into the concrete through cracks which reacts with calcium hydroxide formed by the reaction of $\mathrm{C}_{2} \mathrm{~S}$ and $\mathrm{C}_{3} \mathrm{~S}$ with water to form calcium carbonate which makes the concrete more alkaline $[\mathbf{1 , 1 5}]$. Our research focuses on finding suitable counteractive measures to reduce the rate of carbonation and also the impact over the addition of supplementary cementitious materials over the rate of carbonation. Various pozzolanic materials were used in past research to study its impact over the rate of carbonation. For instance, cement treated Toyoura silica sand used under sealed, natural and accelerated carbonation conditions as supplementary cementitious materials shown increased rate of carbonation due to its pore structure and reduction in the formation of calcium hydroxide [2]. With respect to other pozzolanic materials for instance such as silica fume, the optimum level of replacement in reinforced structures should be $10 \%$. Addition beyond $10 \%$ increased the potential risk of carbonation [3]. Various factors such as water-binder ratio,

Revised Manuscript Received on July 22, 2019

*JaganSivamani

JaganSivamani*, Department of Civil Engineering, Kalasalingam Academy of Research and Education, Krishnankoil, India.Email: s.jagan@klu.ac.in fineness of mineral admixtures, nature of carbonation, age of concrete, etc. has direct relationship over the rate of carbonation in concrete. Water-binder ratio has direct impact over the rate of carbonation. Reduction in water-binder ratio especially below 0.38 decreases the rate of carbonation where the role of mineral admixtures was ignored. On the other hand increase in w/c ratio increases the rate of carbonation [4,13and 14]. With respect to the fineness of materials, increase in the fineness of supplementary cementitious materials that were added to concrete increased the rate of carbonation [5, 14]. This is because of the higher surface adsorption of water molecules by finer particles in the concrete. Also cover provided to concrete had less impact over the rate of carbonation which was evident from the research conducted on light reinforced Geopolymer concrete slabs [6]. Rate of carbonation in a concrete as stated earlier can be determined either by natural/ accelerated means. Correspondingly, age of concrete is inter-related with the nature of carbonation. Accelerated rate of carbonation tends to increase the weight of the sample by $6 \%$ as a result of increase in the production of calcite due to accelerated carbonation $[7,16]$. Such increase in the production of calcite will also get increased as the age of exposure of concrete under accelerated carbonation increases $[6,8]$. Apart from the factors stated above, blending of pozzolanic materials either in binary/ ternary system has inverse effect on the carbonation of concrete $[\mathbf{9 , 1 4}$. Considering the effect of all such factors into account, our research focuses on utilizing the $\mathrm{M}$ sand as replacement to River sand, and pozzolanic materials such as fly ash, silica fume and steel slag as a partial replacement to cement to reduce the rate of carbonation. To achieve such objective, accelerated carbonation for the period of about one year is given to the specimens under different combinations by varying the water to cement ratios.

\section{METHODOLOGY}

\section{A. Materials}

Ordinary Portland cement of 53 grade tested for its various physical properties confirming to IS 8112-1989, river sand passing through $2.36 \mathrm{~mm}$ sieve with fineness modulus of 2.73, Coarse aggregate of $20 \mathrm{~mm}$ size with fineness modulus of $6.1, \mathrm{M}$ sand passing through $2.36 \mathrm{~mm}$ sieve, steel slag collected from iron industry locally, Fly Ash collected from thoothukudi thermal power plant, silica fume collected from locally available market and water confirming to IS456-2000 were used in this study. 


\section{B. Mix Proportions}

Mix proportions to study the behaviour of concrete under two different w/c ratios of 0.45 and 0.5 are presented in the table 1 . A total of 50 specimens were prepared under these two w/c ratios. IS 10262 codal provisions for preparation of mix designs were adopted.

Table- I: Mix Proportions

\begin{tabular}{|r|l|c|c|}
\hline S. No & Items & Proportions & Proportions \\
\hline 1 & Cement & $372 \mathrm{Kg} / \mathrm{m}^{3}$ & $413 \mathrm{Kg} / \mathrm{m}^{3}$ \\
\hline 2 & Fine Aggregate & $829 \mathrm{Kg} / \mathrm{m}^{3}$ & $799 \mathrm{Kg} / \mathrm{m}^{3}$ \\
\hline 3 & Coarse Aggregate & $1015 \mathrm{Kg} / \mathrm{m}^{3}$ & $1029 \mathrm{Kg} / \mathrm{m}^{3}$ \\
\hline 4 & w/c ratio & 0.5 & 0.45 \\
\hline
\end{tabular}

\section{Preparation of test specimens}

Concrete cubes of size $150 \mathrm{~mm} * 150 \mathrm{~mm} * 150 \mathrm{~mm}$ was prepared to study the carbonation property of concrete. Cement, River sand, M sand, supplementary cementitious materials and Coarse aggregate were added along with water based on the mix proportions. Added ingredients were then thoroughly mixed in pan mixer for about 6 minutes. After mixing, concrete cubes specimens were filled with mixture at three layers where each layer of concrete was compacted under 25 blows using tamping rod. Finally top surface of the specimens are levelled using trowel to ensure smooth finishing. Specimens were then allowed to set for 24 hours at room temperature, demoulded and cured for 28 days. After 28 days of curing, specimens are kept in carbonation chamber subjected to accelerated carbonation of $2 \%$ for about 1 year. Specimens are then removed from chamber and cut into two halves to measure the rate of carbonation. This was achieved by spraying $1 \%$ of phenolphthalein indicator over the cut specimen's on all four sides to measure the mean penetration of $\mathrm{CO}_{2}$. In our study, RS denotes the river sand, Ms denotes the manufactured sand at $100 \%$ replacement level, RSMs denotes cement replaced by $50 \%$ of silica fume and river sand replaced by $50 \%$ of $\mathrm{M}$ sand, $\mathrm{RM}_{\mathrm{s}} \mathrm{S}$ denotes river sand replaced by $50 \% \mathrm{M}$ sand and 50\% slag, FMs denotes fly ash at $50 \%$ replacement to cement and $\mathrm{M}$ sand at $50 \%$ replacement to river sand.

\section{Testing of specimens}

Carbonation of concrete is determined for the concrete cube specimens at different levels of replacement of supplementary cementitious materials along with $\mathrm{M}$ sand and River sand under two different w/c ratios 0.45 and 0.5 as discussed earlier as shown in the figure 1. Specimens that were casted and cured for 28 days subjected to accelerated carbonation for the period of one year, which was the cut into two halves and sprayed with $1 \%$ of phenolphthalein indicator at all four sides of specimens. Change of colour from pink to colourless indicates the zone of carbonation. Depth of carbonation is then measure using scale on all four directions and mean depth of carbonation for specimens were measured.

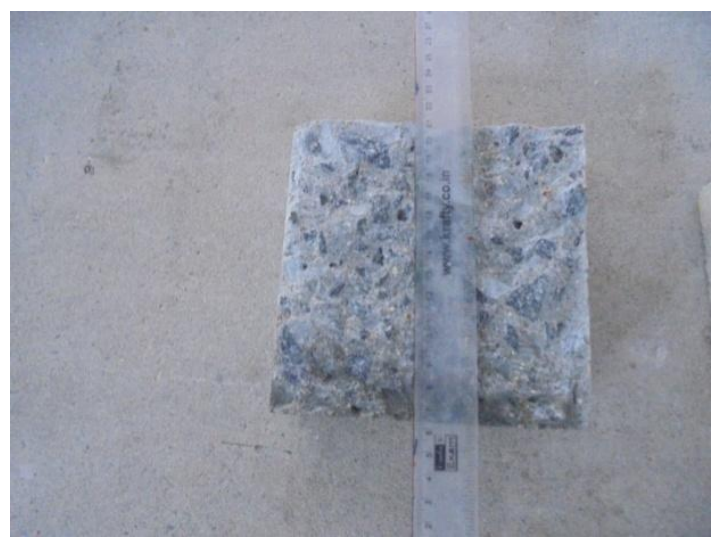

Fig.1.Test set up

\section{RESULTS AND DISCUSSIONS}

Test results of carbonation depth investigated after one year was presented in the table 2 . Also depth of penetration of $\mathrm{CO} 2$ penetration was presented in the figure 2 and 3 . In case of RS, average of median depth of penetration is found to be 1.68 whereas increase in depth of penetration is found to be 1.65 at $\mathrm{w} / \mathrm{c}$ ratio 0.5 . Also as the $\mathrm{w} / \mathrm{c}$ ratio is decreased to 0.45 , average of median depth of penetration is found to 0.39 and increase in depth of penetration is found to be 0.25 . Around 70 to $80 \%$ carbonation depth gets reduced as the w/c ratio is reduced. This is based on the fact that as the w/c ratio is increased, pore structures gets more interconnected providing easy path for the entry of atmospheric agents thereby increasing the rate of carbonation in concrete. With respect to RSMs, average of median depth of penetration is found to 3.09 and increase in depth of penetration is found to be 1.41 at $\mathrm{w} / \mathrm{c}$ ratio 0.5 . Also as the w/c ratio is decreased to 0.45 , average of median depth of penetration is found to 1.45 and increase in depth of penetration is found to be 1.31 . When the w/c ratio is reduced, rate of carbonation depth gets reduced, but the values are far high compared to river sand which was evident from the results provided in the table 2 . This is due to the presence of mineral admixtures like silica fume which is added at equal proportions to cement, which plays a major role in coarsening of pore structures during hydration process leading to the carbonation in concrete. In case of FMs, at $0.5 \mathrm{w} / \mathrm{c}$ ratio, average of median depth of penetration is found to 3.1 and increase in depth of penetration is found to be 2.5 . Also as the w/c ratio is decreased to 0.45 , average of median depth of penetration is found to 2.5 and increase in depth of penetration is found to be 2.25 . In this case when fly ash is added at $50 \%$ replacement level to cement, rate of carbonation of decreases at $0.45 \mathrm{w} / \mathrm{c}$ ratio, but overall perspective the rate of carbonation is higher compared to RS. This is due to the decrease in the percentage of calcium oxide content in fly ash which is consumed totally by atmospheric $\mathrm{CO} 2$ decreasing its resistance to carbonation. When steel slag is added along with $\mathrm{M}$ sand as a replacement to river sand, average of median depth of penetration is found to 6.94 and increase in depth of penetration is found to be 0.98 at w/c ratio 0.5 , whereas the average of median depth of penetration gets reduced to 5.97 and increase in depth of penetration was found to be increased by 2.45 to $\mathrm{w} / \mathrm{c}$ 
ratio 0.45. This enormous increase in the depth of carbonation is due to the high porous nature of the steel slag. Steel slag collected from the industry that were used without any further processing tend to have more porosity than to river sand. This in turn generates more interconnected pores furthermore increasing the rate of carbonation. Finally with respect to Ms, average of median depth of penetration is found to 1.20 and increase in depth of penetration is found to be 1.05 at $\mathrm{w} / \mathrm{c}$ ratio 0.5 . Also as the $w / c$ ratio is decreased to 0.45 , average of median depth of penetration is found to 0.63 and increase in depth of penetration is found to be 0.35 . It can be found that the depth of carbonation and increase in depth of carbonation at both w/c 0.5 and 0.45 is very lesser compared to all other mix combinations. At $0.5 \mathrm{w} / \mathrm{c}$ ratio, increase in depth of penetration of Ms was $38 \%$ lesser compared to Rs (which has least depth of carbonation compared to other mix combinations) and at $0.45 \mathrm{w} / \mathrm{c}$ ratio increase in depth of penetration of Ms was $24 \%$ lesser compared to Rs. This is because of the usage of $\mathrm{M}$ sand, which was collected from the quarry after various manufacturing and treatment processes. As we know, higher the porosity, higher will be the rate of carbonation in concrete. Such processed M sand had good particle packing characteristics, which in turn reduces the formation of pores in concrete. This ultimately reduces the rate of carbonation in concrete.

Table- II: Depth of $\mathrm{CO}_{2}$ penetrated

\begin{tabular}{|c|c|c|c|c|c|c|c|}
\hline $\begin{array}{c}\text { Mix } \\
\text { Id }\end{array}$ & $\begin{array}{c}\mathbf{1}^{\mathrm{st}} \\
\mathbf{m m}\end{array}$ & $\begin{array}{c}2^{\text {nd }} \\
\mathbf{m m}\end{array}$ & $\begin{array}{c}3^{\text {rd }} \\
\mathbf{m m}\end{array}$ & $\begin{array}{c}4^{\text {th }} \\
\mathrm{mm}\end{array}$ & $\begin{array}{c}\text { Min } \\
(\mathbf{m m})\end{array}$ & $\begin{array}{r}\text { Max } \\
(\mathbf{m m})\end{array}$ & $\underset{\mathbf{n}}{\text { Media }}$ \\
\hline \multirow{5}{*}{ M1 } & 0.4 & 0.1 & 0.4 & 0.5 & 0.1 & 0.5 & 0.3 \\
\hline & 1.2 & 0.5 & 0.1 & 0.3 & 0.1 & 1.2 & 0.65 \\
\hline & 1.1 & 0.4 & 0.5 & 0.4 & 0.4 & 1.1 & 0.75 \\
\hline & 3.1 & 3 & 0 & 3 & 0 & 3.1 & 1.55 \\
\hline & 3 & 1 & 2 & 1 & 1 & 3 & 2 \\
\hline \multirow{5}{*}{ M2 } & 0.5 & 1.1 & 1.4 & 0.4 & 0.4 & 1.4 & 0.9 \\
\hline & 0.4 & 0.6 & 0.4 & 1.2 & 0.4 & 1.2 & 0.8 \\
\hline & 1.2 & 0.6 & 0.7 & 0.4 & 0.4 & 1.2 & 0.8 \\
\hline & 0.4 & 0.4 & 0.6 & 0.4 & 0.4 & 0.6 & 0.5 \\
\hline & 0 & 0 & 0.5 & 0.4 & 0 & 0.5 & 0.25 \\
\hline \multirow{5}{*}{ M3 } & 3 & 2.2 & 2.8 & 0.2 & 0.2 & 3 & 1.6 \\
\hline & 2.5 & 0.3 & 0.5 & 0.4 & 0.3 & 2.5 & 1.4 \\
\hline & 2.1 & 1 & 2 & 0 & 0 & 2.1 & 1.05 \\
\hline & 3.1 & 0 & 0.4 & 0.7 & 0 & 3.1 & 1.55 \\
\hline & 2.5 & 0.2 & 1.9 & 3.1 & 0.2 & 3.1 & 1.65 \\
\hline \multirow{4}{*}{ M4 } & 3 & 2.8 & 1.5 & 1.3 & 1.3 & 3 & 2.15 \\
\hline & 5 & 4.3 & 3 & 2.4 & 2.4 & 5 & 3.7 \\
\hline & 6 & 2 & 3 & 5.5 & 2 & 6 & 4 \\
\hline & 3 & 2 & 4 & 1 & 1 & 4 & 2.5 \\
\hline
\end{tabular}

\begin{tabular}{|c|c|c|c|c|c|c|c|}
\hline & 4 & 2.6 & 3 & 2.5 & 2 & 6 & 3.5 \\
\hline \multirow{5}{*}{ M5 } & 0 & 5 & 5 & 2.2 & 0 & 5 & 2.5 \\
\hline & 0 & 5 & 3 & 3.5 & 0 & 5 & 2.5 \\
\hline & 4 & 1 & 5.5 & 6.2 & 1 & 6.2 & 3.6 \\
\hline & 6 & 4 & 0 & 3.5 & 0 & 6 & 3 \\
\hline & 5.2 & 5.8 & 8.3 & 0 & 0 & 8.3 & 4.15 \\
\hline \multirow{5}{*}{ M6 } & 7 & 6 & 0 & 4 & 0 & 7 & 3.5 \\
\hline & 4 & 4 & 2 & 0 & 0 & 4 & 2 \\
\hline & 3.5 & 0 & 3.3 & 3.7 & 0 & 3.7 & 1.85 \\
\hline & 4.5 & 4 & 3.5 & 0 & 0 & 4.5 & 2.25 \\
\hline & 0 & 0 & 4.8 & 0 & 0 & 4.8 & 2.4 \\
\hline \multirow{5}{*}{ M7 } & 6 & 6.3 & 6.1 & 5.8 & 5.8 & 6.3 & 6.05 \\
\hline & 8.2 & 8.1 & 4.2 & 7.2 & 4.2 & 8.2 & 6.2 \\
\hline & 8.3 & 8.9 & 6.3 & 7.1 & 6.3 & 8.9 & 7.6 \\
\hline & 9.1 & 8.5 & 8.6 & 8.8 & 8.5 & 9.1 & 8.8 \\
\hline & 7.2 & 4.5 & 6.8 & 7.6 & 4.5 & 7.6 & 6.05 \\
\hline \multirow{5}{*}{ M8 } & 3 & 2.2 & 7 & 0 & 0 & 7 & 3.5 \\
\hline & 7.3 & 10 & 7.9 & 7.4 & 7.3 & 10 & 8.65 \\
\hline & 9.5 & 4.2 & 5.5 & 5.8 & 4.2 & 9.5 & 6.85 \\
\hline & 6 & 4.5 & 5.8 & 2.2 & 2.2 & 6 & 4.1 \\
\hline & 7 & 5 & 5.2 & 1.5 & 1.5 & 7 & 4.25 \\
\hline \multirow{5}{*}{ M9 } & 5 & 4.5 & 0 & 2.2 & 0 & 5 & 2.5 \\
\hline & 4 & 3 & 0 & 0 & 0 & 4 & 2 \\
\hline & 0 & 1.5 & 0 & 1.1 & 0 & 1.5 & 0.75 \\
\hline & 0 & 0 & 1.1 & 0.5 & 0 & 1.1 & 0.55 \\
\hline & 4.2 & 2.5 & 0.4 & 0.2 & 0.2 & 4.2 & 2.2 \\
\hline \multirow{5}{*}{$\begin{array}{c}\text { M1 } \\
0\end{array}$} & 0.4 & 0.3 & 0.6 & 0.4 & 0.3 & 0.6 & 0.45 \\
\hline & 0.5 & 0.4 & 0.5 & 0.4 & 0.4 & 0.5 & 0.45 \\
\hline & 0 & 0 & 0.3 & 0.7 & 0 & 0.7 & 0.35 \\
\hline & 0.5 & 0.6 & 0 & 0.3 & 0 & 0.6 & 0.3 \\
\hline & 0 & 0.6 & 0.5 & 0.2 & 0 & 0.6 & 0.3 \\
\hline
\end{tabular}

${ }^{*} \mathrm{M} 1-\mathrm{M}_{\mathrm{s}}(0.5 \mathrm{w} / \mathrm{c})$

$\mathrm{M} 2-\mathrm{M}_{\mathrm{s}}(0.45 \mathrm{w} / \mathrm{c})$

RSM $(0.45 \mathrm{w} / \mathrm{c})$

M6 - FM ${ }_{\mathrm{s}}(0.45 \mathrm{w} / \mathrm{c})$

$\mathrm{M} 7-\mathrm{RM}_{\mathrm{s}} \mathrm{S}(0.5 \mathrm{w} / \mathrm{c})$

$\mathrm{M} 8-\mathrm{RM}_{\mathrm{s}} \mathrm{S}(0.45 \mathrm{w} / \mathrm{c})$

$\mathrm{M} 9-\mathrm{R}_{\mathrm{s}}(0.5 \mathrm{w} / \mathrm{c})$

$\mathrm{M} 10-\mathrm{R}_{\mathrm{S}}(0.45 \mathrm{w} / \mathrm{c})$ 


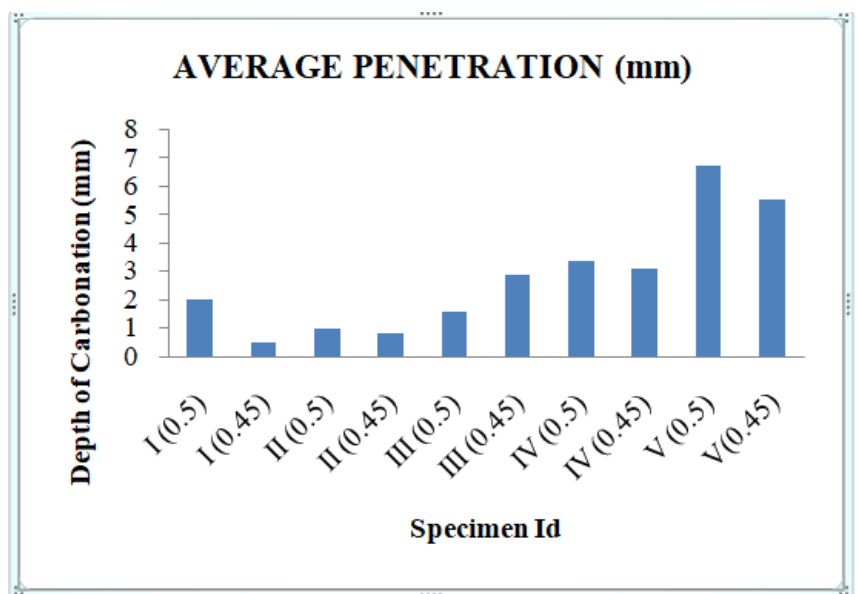

Fig.2.Rate of Carbonation

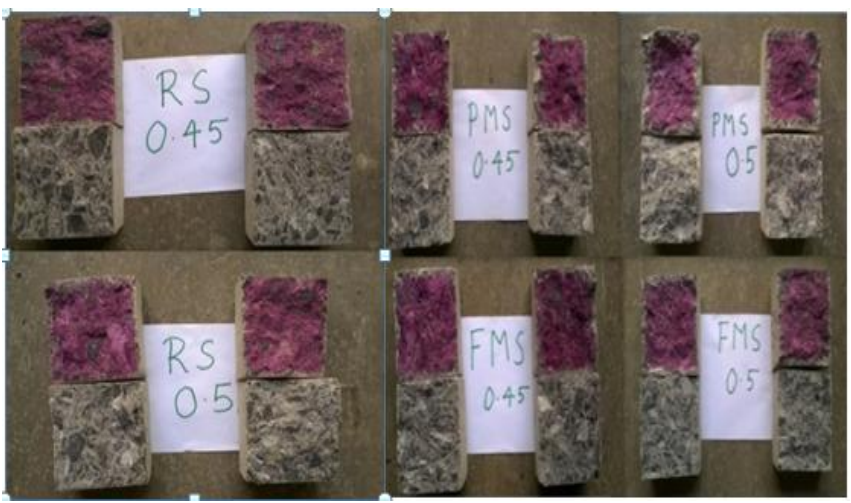

Fig.3.Indication of depth of $\mathrm{CO}_{2}$ penetrated

\section{CONCLUSION}

From the experimental investigation, it could be concluded that

- The depth of carbonation is less in case of w/c ratio 0.45 compared to $0.5 \mathrm{w} / \mathrm{c}$. As discussed earlier, reduction in $\mathrm{w} / \mathrm{c}$ ratio reduces the interconnectivity of pores in concrete, thereby reducing the rate of carbonation in concrete[4, 13 and 14].

- Carbonation in M sand concrete is lesser compared to other mix combinations of concrete. This is mainly due to the good particle packing achieved by processing method of $\mathrm{M}$ sand from quarries.

- When supplementary cementitious materials were added, depth of carbonation is found to be increased.

- Depth of carbonation is more in concrete made with fly ash and $\mathrm{M}$ sand. When reinforcement in used in concrete, passive layer formed around the steel will get affected by the formation of $\mathrm{CaCO}_{3}$ due to lower content of $\mathrm{CaO}$ in fly ash.

- Overall the rate of carbonation in steel slag based concrete mixes is more compared to all others due to higher porous nature of steel slag used.

- Usage of $\mathrm{M}$ sand in concrete as complete replacement to river sand will improve the durability by reducing the carbonation of concrete. Also it is proven to be beneficial in terms of sustainability and scarcity.

\section{REFERENCES}

1. N Venkat Rao and $\mathrm{T}$ Meena, "A review on carbonation study in concrete" IOP conference series: Materials science and Engineering, vol. 263, Aug. 2017, pp. 240-248.

2. KenichiroNakarai and Tomomi Yoshida, "Effect of carbonation on strength development of cement treated Toyoura Silica Sand" Construction and Building Materials., vol. 55, April. 2015, pp. 857-865.

3. MarlovaKulakowski, Fernanda M. Pereira, Denise C.C. Dal Molin, "Carbonation-induced reinforcement corrosion in silica fume concrete" Construction and Building Materials., vol. 23, October. 2009, pp. 1189-1195.

4. LaijiuZheng, Shin-ici Kuroda, Huawa Liu, Bing Du, Ju Wei and Yuping Zhao, "Study on Carbonization test of Manufactured Sand Concrete" Construction and Building Materials., vol. 26, Dec. 2013, pp. 1036-1040.

5. Amnon Katz and Hadassa Baum, "Effect of high levels of fines content on Concrete Properties" ACI Material Journal., vol. 1, Feb. 2006, pp. 474-482.

6. Sandeep S, Dr. Manjunatha N Hegde and T. Chandrasekaraiah, "Experimental Study of Accelerated Carbonation effects on Lightly Reinforced Geopolymer Concrete Slabs" International Journal of Engineering Research and Technology, vol. 3, Mar. 2014, pp. 1061-1067.

7. G. Cultrone, E. Sebastian and M. Ortega Huertas, "Forced and Natural Carbonation of lime-based mortars with and without additives: Mineralogical and textural changes" Cement and Concrete Research, vol. 35, Aug. 2005, pp. 2278-2289.

8. Supritha R.M, Shashishankar A, B. Shivakumaraswamy and R. Abhilash, "Effect of Carbonation on Self Compacting Concrete with GGBS and Silica fume" International Journal of Civil Engineering Research, vol. 7, Dec. 2016, pp. 67-77.

9. Eehab Ahmed Badreldin Khalil and Mohamed Anwar, "Carbonation of ternary cementitious concrete systems containing fly ash and silica fume" Water Science, vol. 29, Dec. 2015, pp. 36-44.

10. A. Jayaraman, M. Saravanana and Dr. G. Anusha, "Comparative Study on M-sand Concrete and (Nano-Silica with M-sand Concrete)" International Journal of Scientific Engineering and Technology Research, vol. 3, Sep. 2014, pp. 45-56.

11. P Daisy Angelin and P Ravi Kishore, "Durability Studies on Concrete with Manufacturing Sand as a Partial replacement of fine aggregate in HCL Solution" International Journal of Engineering Research and Development, vol. 11, Aug. 2015, pp. 44-50.

12. Roshni K G, Vineeth P C, "Strength and Durability Studies on Concrete Containing Foundry Sand and GGBS" International Journal of Research in Advent Technology, vol. 1, July. 2015, pp. 10-11.

13. E. Rozière, A. Loukili, \& G. Pijaudier-Cabot, "Experimental study on concrete carbonation to work out performance-based specifications" Framcos triennial conference, Japan, May. 2007.

14. Manish Kumar, Nishant Malay and JituKujur, "Study of natural carbonation of concrete incorporating marble dust" Construction materials, vol. 171, July. 2018, pp. 155-163.

15. Chávez-Ulloa1,R. Camacho-Chab, M.Sosa-Baz, P. Castro-Borges andT.Pérez-López, "Corrosion Process of Reinforced Concrete by Carbonation in a Natural Environment and an Accelerated Test Chamber" International Journal of Electrochemical Science, vol. 8 , May. 2013, pp. 121-129.

\section{AUTHORS PROFILE}

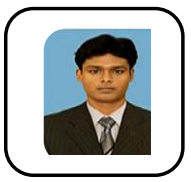

JaganSivamanicompleted $M$. Tech in Structural Engineering from VIT University in 2015, B.Tech in Civil Engineering from Kongu Engineering College in 2013. I am currently working as Assistant Professor at Kalasalingam Academy of Research and Education. During my career I have published my research worked in 8reputed International Journals and also attended many International conferences, workshops and seminars Also, a life member of IAENG association. 